\title{
Lifetime prevalence, sociodemographic predictors, and comorbidities of oppositional defiant disorder: the National Epidemiology of Iranian Child and Adolescent Psychiatric disorders (IRCAP)
}

Mohammad Reza Mohammadi, ${ }^{1}$ Maryam Salmanian, ${ }^{1}$ iD Zahra Hooshyari, ${ }^{1}$ Alia Shakiba, Seyyed Salman Alavi, ${ }^{1}$ Ameneh Ahmadi, ${ }^{1}$ Ali Khaleghi, ${ }^{1}$ Hadi Zarafshan, ${ }^{1}$ Seyed Ali Mostafavi, ${ }^{1}$ Anita Alaghmand, ${ }^{2}$ Parviz Molavi, ${ }^{3}$ Javad Mahmoudi-Gharaei, ${ }^{1}$ Koorosh Kamali, ${ }^{4}$ Ahmad Ghanizadeh, ${ }^{5}$ Hedayat Nazari, ${ }^{6}$ Nasrin Sarraf, ${ }^{7}$ Ahmad Ahmadipour, ${ }^{8}$ Firoozeh Derakhshanpour, ${ }^{9}$ Forough Riahi, ${ }^{10}$ Atieh Golbon, ${ }^{11}$ Maryam Kousha, ${ }^{12}$ Aazam Sadat Heydari Yazdi, ${ }^{13}$ Mahin Eslami Shahrbabaki, ${ }^{14}$ Naser Hajian Motlagh, ${ }^{15}$ Houshang Amirian, ${ }^{16}$ Azizollah Mojahed, ${ }^{17}$ Arezou Kiani, ${ }^{18}$ Mohammad Ahmadpanah, ${ }^{19}$ Reza Dastjerdi, ${ }^{20}$ Nastaran Ahmadi ${ }^{21}$

\begin{abstract}
${ }^{1}$ Psychiatry and Psychology Research Center, Roozbeh Hospital, Tehran University of Medical Sciences, Tehran, Iran. ${ }^{2}$ Department of Psychiatry, Arak University of Medical Sciences, Arak, Iran. ${ }^{3}$ Department of Psychiatry, Fatemi Hospital, Ardabil University of Medical Sciences, Ardebil, Iran. ${ }^{4}$ Department of Public Health, School of Public Health, Zanjan University of Medical Sciences, Zanjan, Iran. ${ }^{5}$ Department of Psychiatry, Hafez Hospital, Shiraz University of Medical Sciences, Shiraz, Iran. ${ }^{6}$ Department of Psychiatry, School of Medicine, Lorestan University of Medical Sciences, Khorram Abad, Iran. ${ }^{7}$ Department of Child and Adolescent Psychiatry, School of Medicine, Qazvin University of Medical Sciences, Qazvin, Iran. ${ }^{8}$ Department of Psychiatry, Booshehr University of Medical Sciences, Khalij-E Fars Hospital, Booshehr, Iran. ${ }^{9}$ Golestan Psychiatric Research Center, Gholestan University of Medical Sciences, Gholestan, Iran. ${ }^{10}$ Department of Psychiatry, Jondi Shapour University, Ahvaz, Iran. ${ }^{11}$ Department of Psychiatry, Hormozgan University of Medical Sciences, Bandar Abbas, Iran. ${ }^{12}$ Department of Pediatric Psychiatry, Guilan University of Medical Sciences, Rasht, Iran. ${ }^{13}$ Psychiatry and Behavioral Sciences Research Center, Mashhad University of Medical Sciences, Mashhad, Iran. ${ }^{14}$ Department of Psychiatry, Neuroscience Research Center and Institute of Neuropharmachology, Kerman University of Medical Sciences, Kerman, Iran. ${ }^{15}$ Alborz University of Medical Sciences, Karaj, Iran. ${ }^{16}$ Department of Psychiatry, School of Medicine, Kermanshah University of Medical Sciences, Kermanshah, Iran. ${ }^{17}$ Department of Clinical Psychology, Zahedan University of Medical Sciences, Zahedan, Iran. ${ }^{18}$ Urmia University of Medical Sciences, Urmia, Iran. ${ }^{19}$ Research Center for Behavioral Disorders and Substance Abuse, Hamadan University of Medical Sciences, Hamadan, Iran. ${ }^{20}$ Birjand University of Medical Sciences, Birjand, Iran. ${ }^{21}$ Yazd Cardiovascular Research Center, Shahid Sadoughi University of Medical Sciences, Yazd, Iran.
\end{abstract}

\begin{abstract}
Objective: This was the first national epidemiological study on oppositional defiant disorder (ODD) in Iran, which provided new information about the prevalence, comorbidities, and sociodemographic predictors of ODD.

Methods: Data from a face-to-face household survey of 30,532 children and adolescents aged 6-18 years were collected from across all 31 provinces of Iran using a multistage cluster sampling design. The Persian version of the Kiddie Schedule for Affective Disorders and Schizophrenia for School-Age Children - Present and Lifetime Version (K-SADS-PL) was used in this study.

Results: The lifetime prevalence of ODD was found to be 3.9\%. ODD was significantly more common in boys than girls and appeared in late adolescence more frequently than in childhood. A lower prevalence of ODD was found among participants who lived in rural areas. ODD is highly likely to cooccur with attention deficit hyperactivity disorder, separation anxiety disorder, generalized anxiety disorder, and depressive disorders.

Conclusions: The findings of this national population-based study confirm and extend previous findings on the prevalence, comorbidities, and sociodemographic predictors of ODD.
\end{abstract}

Keywords: Oppositional defiant disorder (ODD); comorbidity; prevalence; Iran

\section{Introduction}

Oppositional defiant disorder (ODD) is one of the most prevalent psychiatric disorders among children and is

Correspondence: Maryam Salmanian, Tehran University of Medical Sciences, Psychiatry and Psychology Research Center, Roozbeh Hospital, South Kargar Ave, 1333715914, Tehran, Iran.

E-mail: m-salmanian@alumnus.tums.ac.ir

Submitted Jan 30 2019, accepted May 29 2019, Epub Aug 192019. diagnosed through the following characteristics: a pattern of angry or irritable mood, argumentative or defiant behavior, or vindictiveness during childhood or adolescence. $^{1,2}$ Although there are many overlaps between

How to cite this article: Mohammadi MR, Salmanian M, Hooshyari Z, Shakiba A, Alavi SS, Ahmadi A, et al. Lifetime prevalence, sociodemographic predictors, and comorbidities of oppositional defiant disorder: the National Epidemiology of Iranian Child and Adolescent Psychiatric disorders (IRCAP). Braz J Psychiatry. 2020;42:162-167. http://dx.doi.org/10.1590/1516-4446-2019-0416 
ODD and conduct disorder, ${ }^{3,4}$ ODD includes emotional dysregulation problems and less severe behaviors than conduct disorder. ${ }^{1}$ The predictors of ODD include low socioeconomic status, poor social functioning, higher levels of stress and family conflict, parental depression, poor family cohesion, harsh parenting or coercive physical punishment, insecure attachment, low parental acceptance, and parental hostility. ${ }^{5-7}$

The ODD prevalence rate has been reported as $1.4-16 \%$ in population-based samples and $28-50 \%$ in clinical samples. ${ }^{2,6,8}$ ODD is more common in boys than in girls ${ }^{3,6,8}$ and is more prevalent among younger participants; ODD prevalence decreases in late childhood and adolescence in both genders. ${ }^{3,9}$ Moreover, ODD is the most prevalent psychiatric disorder in Iran, with reported rates of $4.45 \%$ among children and adolescents in five populous provinces. ${ }^{10}$ To date, no national epidemiological study has been conducted to show the current prevalence, sociodemographic predictors, and comorbidities of ODD in Iran.

Previous research has reported that $92.4 \%$ of individuals with ODD have another psychiatric disorder ${ }^{9}$ and have a worse prognosis than those with ODD alone. ${ }^{11}$ ODD has strong comorbidity with conduct disorder, attention deficit hyperactivity disorder (ADHD), substance use disorders, and mood and anxiety disorders. . $^{2,7,12-14}$ It is more associated with internalizing disorders, since individuals with ODD have emotional dysregulation problems. ${ }^{2}$ More than $50 \%$ of those with ODD meet the criteria for anxiety disorders and nearly $50 \%$ have a mood disorder. ${ }^{9}$

The goal of this study was to present national epidemiological data that estimate the lifetime prevalence, sociodemographic predictors, and comorbidity of ODD with other conditions among Iranian children and adolescents. Additionally, ODD comorbidity patterns were examined according to age and gender. This study can provide new information on ODD for researchers, clinicians, and healthcare policymakers.

\section{Methods}

\section{Sample}

Data were obtained from the National Epidemiology of Iranian Child and Adolescent Psychiatric Disorders (IRCAP). A face-to-face household survey of 30,532 Persian-speaking children and adolescents aged 6-18 years was conducted in all 31 provinces of Iran using a multistage cluster sampling design. A total of 1,000 children and adolescents were randomly selected from urban and rural areas in each province of Iran according to postal codes. A total of 170 blocks were randomly collected. Six participants were selected from each cluster head: three of each gender from different age groups (6-9, 10-14, and 15-18 years); we categorized age groups according to World Health Organization parameters. ${ }^{15}$ The population proportion of each province was then weighted. The response rate was $92 \%$.

The participants included adolescents aged 11-18 years and the parents of those younger than 11 years old.
They were interviewed by trained psychologists using the Persian version of Kiddie Schedule for Affective Disorders and Schizophrenia for School-Age Children Present and Lifetime Version (K-SADS-PL). Sociodemographic factors, including gender, age, type of settlement, education level of the mother and father, and history of psychiatric hospitalization of the mother and father were collected.

\section{Assessment}

The K-SADS-PL is a semi-structured psychiatric interview based on the DSM-IV criteria and includes mood disorders, psychotic disorders, anxiety disorders, conduct disorder, ODD, ADHD, eating disorders, elimination disorders, and tic disorder. The reliability and validity of ODD diagnosis by the Persian version of the K-SADS-PL have been reported as 0.81 and 0.92 , respectively. ${ }^{16}$

\section{Statistical analysis}

The data were analyzed using SPSS version 20. Descriptive data are presented as frequency, percentage, mean, and standard deviation. The sociodemographic predictors of ODD were used to estimate associations with ODD using logistic regression analysis. In addition, comorbidities of ODD with other psychiatric disorders were examined using logistic regression analysis based on gender and age. The data were adjusted based on population weighting for each province. P-values less than 0.05 were considered statistically significant.

\section{Ethics statement}

This study was approved by the research ethics committee of the National Institute for Medical Research Development (NIMAD; Tehran, Iran; ref. IR.NIMAD.REC. 1395.001). Full details of the method are available in the study protocol. ${ }^{17}$ Data can be requested from the first author (MRM) upon reasonable demand and by permission of the NIMAD.

\section{Results}

A total of 30,532 children and adolescents participated in this survey, and 29,832 individuals responded to the ODD module. No significant differences were observed in sociodemographic predictors of ODD between respondents and non-respondents. The lifetime prevalence of ODD was estimated at $3.9 \%$. According to the univariate and multivariate analysis, significant differences were observed in the sociodemographic characteristics of ODD, including gender, age, type of settlement, mother's education, and mother's history of psychiatric hospitalization (Table 1).

ODD was significantly less prevalent among girls than boys (odds ratio $[\mathrm{OR}]=0.70,95 \%$ confidence interval $(95 \% \mathrm{Cl})=0.60-0.82, \mathrm{p}<0.01)$. A total of 457 girls $(3.2 \%)$ and 667 boys (4.6\%) were diagnosed with ODD. As demonstrated in Table 1 and Figure 1, ODD was significantly more common among 15-18-year-olds than among 6-9-year-olds 
Table 1 Distribution of the study participants' sociodemographic characteristics based on univariate and multivariate analysis

\begin{tabular}{|c|c|c|c|c|c|}
\hline \multirow[b]{2}{*}{ Sociodemographic characteristics } & \multirow[b]{2}{*}{ Total, n (\%) } & \multicolumn{2}{|c|}{ With ODD disorders } & \multicolumn{2}{|c|}{ Logistic regression model, OR $(95 \% \mathrm{Cl})$} \\
\hline & & n (crude percent) & Weighted percent $(95 \% \mathrm{Cl})$ & Univariate & Multivariate \\
\hline \multicolumn{6}{|l|}{ Gender } \\
\hline Boy & $14,601(48.9)$ & $667(4.6)$ & $4.6(4.2-5.04)$ & \multicolumn{2}{|c|}{ Baseline } \\
\hline Girl & $15,231(51.1)$ & $457(3)$ & $3.2(2.9-3.6)$ & $0.69(0.6-0.8)^{*}$ & $0.70(0.60-0.82) *$ \\
\hline \multicolumn{6}{|l|}{ Age (years) } \\
\hline $6-9$ & $10,168(34.1)$ & $332(3.3)$ & $3.6(3.2-4.1)$ & \multicolumn{2}{|c|}{ Baseline } \\
\hline $10-14$ & $10,447(35)$ & 393 (3.8) & 3.7 (3.3-4.2) & $1.02(0.85-1.23)$ & $1.03(0.86-1.2)$ \\
\hline $15-18$ & $9,217(30.9)$ & $399(4.3)$ & $4.6(4.0-5.1)$ & $1.23(1.01-1.48)^{*}$ & $1.28(1.07-1.54)^{*}$ \\
\hline \multicolumn{6}{|l|}{ Type of settlement } \\
\hline Urban & $24,878(83.4)$ & $974(3.9)$ & $4.1(3.8-4.4)$ & \multicolumn{2}{|c|}{ Baseline } \\
\hline Rural & $4,954(16.6)$ & $150(3)$ & $2.7(2.1-3.5)$ & $0.61(0.46-0.83)^{*}$ & $0.67(0.51-0.88) *$ \\
\hline \multicolumn{6}{|l|}{ Father's education } \\
\hline Illiterate & $1,289(4.5)$ & $51(4)$ & $3.5(2.4-5.1)$ & \multicolumn{2}{|c|}{ Baseline } \\
\hline Primary education & $4,633(16.1)$ & $206(4.4)$ & $4.2(3.5-5.0)$ & $1.22(0.78-1.89)$ & $1.16(0.83-1.63)$ \\
\hline Secondary or higher education & $6,400(22.3)$ & $263(4.1)$ & $4.1(3.5-4.7)$ & $1.17(0.76-1.81)$ & $1.06(0.75-1.5)$ \\
\hline College diploma & $8,367(29.1)$ & $288(3.4)$ & $3.7(3.3-4.2)$ & $1.07(0.70-1.63)$ & $0.91(0.63-1.31)$ \\
\hline Bachelor's degree & $6,067(21.1)$ & 208 (3.4) & $4(3.4-4.6)$ & $1.15(0.74-1.76)$ & $0.96(0.65-1.4)$ \\
\hline Master's or higher degree & $1,971(6.9)$ & $60(3)$ & $3.4(2.5-4.5)$ & $0.97(0.59-1.59)$ & $0.92(0.58-1.44)$ \\
\hline Missing & 1,105 & & & & \\
\hline \multicolumn{6}{|l|}{ Mother's education } \\
\hline Illiterate & $1,693(5.8)$ & $75(4.4)$ & $3.7(2.7-5.1)$ & \multicolumn{2}{|c|}{ Baseline } \\
\hline Primary education & $5,482(18.9)$ & $241(4.4)$ & $4.3(3.6-5.1)$ & $1.18(0.81-1.73)$ & $0.99(0.73-1.32)$ \\
\hline Secondary or higher education & $5,679(19.6)$ & $242(4.3)$ & $4.8(4.1-5.5)$ & $1.31(0.9-1.9)$ & $0.95(0.70-1.3)$ \\
\hline College diploma & $8,367(29.1)$ & $350(3.6)$ & $3.7(3.3-4.2)$ & $1.01(0.71-1.45)$ & $0.85(0.62-1.17)$ \\
\hline Bachelor's degree & $6,067(21.1)$ & $181(3.2)$ & $3.9(3.3-4.5)$ & $1.05(0.72-1.53)$ & $0.77(0.54-1.09)$ \\
\hline Master's or higher degree & $1,971(6.9)$ & $22(2.2)$ & $2(1.2-3.3)$ & $0.51(0.27-0.96)^{\dagger}$ & $0.53(0.31-0.91)^{\dagger}$ \\
\hline Missing & 1,105 & & & & \\
\hline \multirow{2}{*}{\multicolumn{6}{|c|}{$\begin{array}{l}\text { History of psychiatric hospitalization } \\
\text { Father }\end{array}$}} \\
\hline & & & & & \\
\hline Yes & $107(0.4)$ & $8(7.5)$ & $6.9(2.7-16.4)$ & \multicolumn{2}{|c|}{ Baseline } \\
\hline No & 29,725 (99.6) & $1,116(3.8)$ & $3.9(3.6-4.2)$ & $0.62(0.21-1.81)$ & $0.74(0.25-2.21)$ \\
\hline \multicolumn{6}{|l|}{ Mother } \\
\hline Yes & $88(0.3)$ & $10(11.4)$ & $17.5(10-28.6)$ & \multicolumn{2}{|c|}{ Baseline } \\
\hline No & 29,744 (99.7) & $1,114(3.7)$ & $3.9(3.6-4.2)$ & $0.190(0.1-0.37)^{*}$ & $0.19(0.1-0.38)^{*}$ \\
\hline Total & $29,832(100)$ & $1,124(3.8)$ & 3.9 & & \\
\hline
\end{tabular}

OR $(95 \% \mathrm{Cl})=$ odds ratio $(95 \%$ confidence interval); ODD = oppositional defiant disorder.

$* p<0.01 ; \uparrow \leqslant 0.05$.

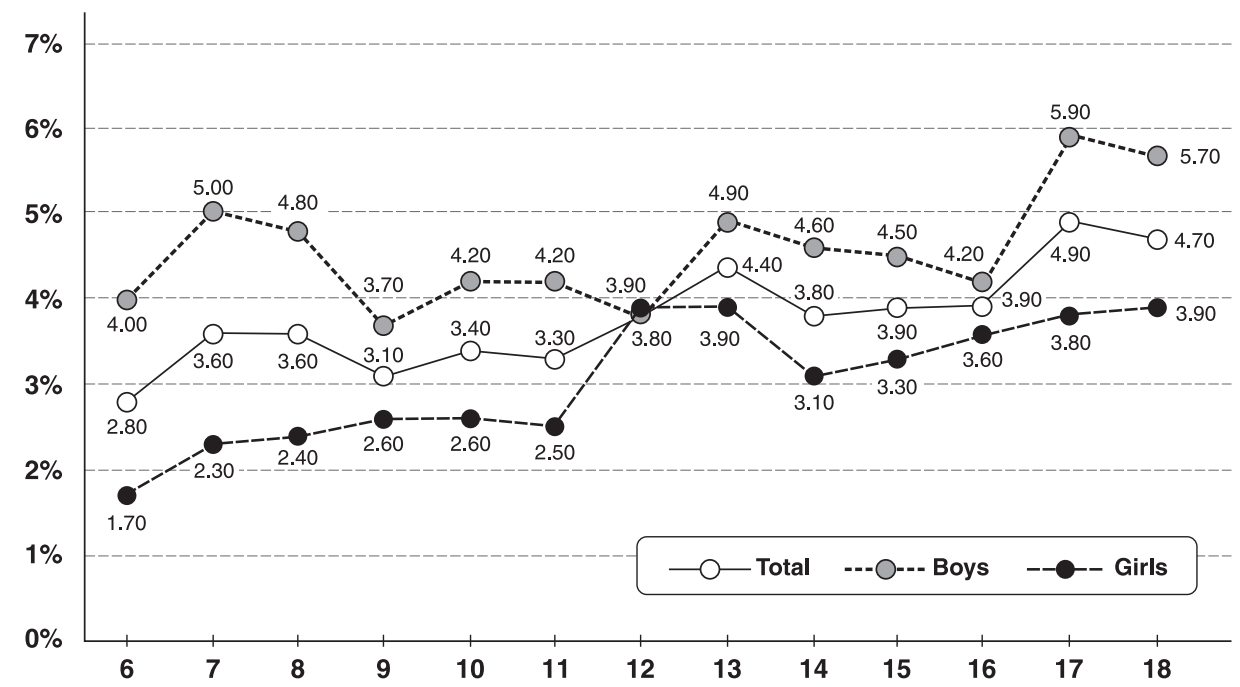

Figure 1 Rates of oppositional defiant disorder by age and gender. 
$(\mathrm{OR}=1.23,95 \% \mathrm{Cl}=1.01-1.48, \mathrm{p}<0.01)$. ODD was significantly less common among rural than urban participants $(\mathrm{OR}=0.61,95 \% \mathrm{Cl}=0.46-0.83, \mathrm{p}<0.01)$. Moreover, ODD was significantly less prevalent among those whose mothers had a Master's degree or higher $(\mathrm{OR}=0.53,95 \%$ $\mathrm{Cl}=0.31-0.91, \mathrm{p}<0.01)$. Additionally, participants whose mothers had no history of psychiatric hospitalization were less likely to experience ODD than those who did $(\mathrm{OR}=$ $0.19,95 \% \mathrm{Cl}=0.1-0.38, \mathrm{p}<0.01)$ (Table 1).

Of the participants with ODD, $71.4 \%$ met the criteria for at least one other psychiatric disorder. As shown in Table 2, ODD is much more likely to co-occur with ADHD (28.9\%), separation anxiety disorder (20.3\%), generalized anxiety disorder (14.9\%), or depressive disorders (13.9\%). However, it is not likely to occur with bulimia nervosa $(0.3 \%)$, encopresis $(0.4 \%)$, panic disorder, or autism (0.5\%).

As shown in Table 3, compared to boys, higher prevalence rates for mood disorders and anxiety disorders, as well as a lower prevalence rate for behavioral disorders, were found among girls with ODD. Among 15-18-year-olds

Table 2 Psychiatric disorder comorbidity rates in children and adolescents with oppositional defiant disorder

\begin{tabular}{|c|c|c|}
\hline Psychiatric disorders & $\mathrm{n}(\%)$ & $95 \% \mathrm{Cl}$ \\
\hline \multicolumn{3}{|l|}{ Mood } \\
\hline Depressive & $156(13.9)$ & $11.98-16.02$ \\
\hline Mania & $15(1.3)$ & $0.8-2.18$ \\
\hline Hypomania & $21(1.9)$ & $1.23-2.84$ \\
\hline \multicolumn{3}{|l|}{ Psychotic } \\
\hline Psychosis & $28(2.5)$ & $1.73-3.58$ \\
\hline \multicolumn{3}{|l|}{ Anxiety } \\
\hline Panic & $6(0.5)$ & $0.24-1.15$ \\
\hline Separation anxiety & $228(20.3)$ & $18.03-22.73$ \\
\hline Social phobia & $90(8.0)$ & $6.56-9.74$ \\
\hline Specific phobias & $121(10.8)$ & $9.09-12.72$ \\
\hline Agoraphobia & $107(9.5)$ & $7.94-11.38$ \\
\hline Generalized anxiety & 167 (14.9) & $12.9-17.06$ \\
\hline Obsessive compulsive & $123(10.9)$ & $9.25-12.9$ \\
\hline Post-traumatic stress & $44(3.9)$ & $2.92-5.21$ \\
\hline \multicolumn{3}{|l|}{ Behavioral } \\
\hline Attention deficit hyperactivity & $318(28.9)$ & $25.73-30.99$ \\
\hline Conduct & 129 (11.5) & $9.75-13.48$ \\
\hline Tic & $55(4.9)$ & $3.78-6.31$ \\
\hline \multicolumn{3}{|l|}{ Neurodevelopmental } \\
\hline Autism & $6(0.5)$ & $0.24-1.15$ \\
\hline Mental retardation & $40(3.6)$ & $2.63-4.81$ \\
\hline Epilepsy & $60(5.3)$ & $4.17-6.81$ \\
\hline \multicolumn{3}{|l|}{ Substance abuse } \\
\hline Smoking & $95(8.5)$ & $6.96-10.22$ \\
\hline Alcohol abuse & $14(1.2)$ & $0.75-2.09$ \\
\hline \multicolumn{3}{|l|}{ Elimination } \\
\hline Enuresis & $140(12.5)$ & $10.66-14.52$ \\
\hline Encopresis & $4(0.4)$ & $0.14-0.92$ \\
\hline \multicolumn{3}{|l|}{ Eating } \\
\hline Anorexia & $0(0.0)$ & $0.00-0.00$ \\
\hline Bulimia & $3(0.3)$ & $0.09-0.79$ \\
\hline Total comorbid & $795(71.4)$ & $0.68-0.73$ \\
\hline
\end{tabular}

$95 \% \mathrm{Cl}=95 \%$ confidence interval. with ODD, mood disorders, psychotic symptoms, and substance abuse disorders were significantly more common, although anxiety disorders and behavioral disorders were significantly less prevalent. Mood disorders were significantly more prevalent and behavioral disorders were significantly lower among 10-14-year-olds with ODD than among 6-9-year-olds with ODD (Table 3).

\section{Discussion}

This study was nationally representative, covered an extensive age range in both genders, and presented findings on comorbidities separately for age- and genderspecific groups of children and adolescents. The findings confirmed and extended previous reports. A lifetime ODD prevalence of $3.9 \%$ was observed, being significantly more common in boys than in girls. However, gender differences in ODD are not considered similar to those in conduct disorder or ADHD. ${ }^{3,8,18}$ In contrast with previous studies, ODD was significantly more common in late adolescence than childhood. ${ }^{9,19}$ However, Nock et al. ${ }^{9}$ reported that ODD has an ascending trend with increased age. The inconsistency of the present study with previous reports should be studied. The present findings also highlight the need for early intervention to prevent ODD repercussions in adolescence.

Although the present results indicate that rural residence was a protective factor, with a lower ODD prevalence among rural than urban participants, Lopez-Villalobos et al. ${ }^{19}$ reported a higher ODD prevalence in rural areas. However, several studies have demonstrated that more risk factors and difficulties exist for urban than rural populations. $^{20}$ Moreover, urban males reported more conflict and externalizing behaviors. ${ }^{21}$ Thus, community and family networks in rural areas can protect children and adolescents against behavioral and emotional problems and delinquency. ${ }^{22}$ Since communities are moving toward urbanization, it can be understood that increased urbanization is associated with increased ODD prevalence.

Mothers play a key role in child-rearing in Iran. In this study, it was found that having a mother with a Master's degree or higher and/or a mother with no history of psychiatric hospitalization were protective factors for ODD in children and adolescents. Additionally, a positive family history of psychiatric hospitalization could represent biologic/genetic predisposition. Previous studies have demonstrated that mothers with lower educational levels had a lower quality of life and were more likely to have children with oppositional defiant symptoms. ${ }^{23}$ Likewise, psychiatric problems, such as depressive and anxiety disorders, interpersonal difficulties, negative emotions, and hostility, were reported in mothers of children with ODD, ${ }^{24}$ which could be considered a consequence or cause of ODD.

The majority of children and adolescents with ODD had at least one other psychiatric disorder. ADHD had the greatest degree of comorbidity with ODD, which confirmed the results of previous studies. ${ }^{3,11,12,14}$ Although some studies have considered ODD as a type of ADHD, others disagree, reporting that ODD and ADHD symptoms develop in parallel, ${ }^{25}$ i.e., the close coincidence of 
Table 3 Psychiatric disorder comorbidity rates in children and adolescents with oppositional defiant disorder by age and gender - based on logistic regression model

\begin{tabular}{|c|c|c|c|c|c|c|c|}
\hline Psychiatric disorders & Total n (\%), (95\%Cl) & Sex & $\mathrm{n}(\%)$ & OR $(95 \% \mathrm{Cl})$ & Age group & n (\%) & OR $(95 \% \mathrm{Cl})$ \\
\hline Mood & $\begin{array}{c}166(14.8) \\
(12.82-16.96)\end{array}$ & $\begin{array}{l}\text { Male } \\
\text { Female }\end{array}$ & $\begin{array}{l}74(11.6) \\
92(20.8)\end{array}$ & $\begin{array}{c}\text { Baseline } \\
2(1.43-2.79)^{*}\end{array}$ & $\begin{array}{c}6-9 \\
10-14 \\
15-18\end{array}$ & $\begin{array}{l}25(8.0) \\
49(12.9) \\
92(24.0)\end{array}$ & $\begin{array}{c}\text { Baseline } \\
1.71(1.03-2.83)^{*} \\
3.64(2.27-5.83)^{*}\end{array}$ \\
\hline Psychotic & $\begin{array}{c}28(2.5) \\
(1.73-3.58)\end{array}$ & $\begin{array}{c}\text { Male } \\
\text { Female }\end{array}$ & $\begin{array}{l}18(2.7) \\
10(2.3)\end{array}$ & $\begin{array}{c}\text { Baseline } \\
0.63(0.38-1.8)\end{array}$ & $\begin{array}{c}6-9 \\
10-14 \\
15-18\end{array}$ & $\begin{array}{c}3(0.9) \\
12(3.1) \\
13(3.3)\end{array}$ & $\begin{array}{c}\text { Baseline } \\
3.46(.97-12.34) \\
3.69(1.04-13.08)^{\dagger}\end{array}$ \\
\hline Anxiety & $\begin{array}{c}474(42.2) \\
(39.31-45.08)\end{array}$ & $\begin{array}{l}\text { Male } \\
\text { Female }\end{array}$ & $\begin{array}{c}26(40.7) \\
214(49.9)\end{array}$ & $\begin{array}{c}\text { Baseline } \\
1.45(1.13-1.86)^{*}\end{array}$ & $\begin{array}{c}6-9 \\
10-14 \\
15-18\end{array}$ & $\begin{array}{l}154(48.4) \\
162(44.4) \\
158(41.0)\end{array}$ & $\begin{array}{c}\text { Baseline } \\
0.85(0.63-1.15) \\
0.74(0.55-1.00)^{\dagger}\end{array}$ \\
\hline Behavioral & $\begin{array}{c}421(37.5), \\
(34.68-40.33)\end{array}$ & $\begin{array}{l}\text { Male } \\
\text { Female }\end{array}$ & $\begin{array}{l}283(43.1) \\
138(31.4)\end{array}$ & $\begin{array}{c}\text { Baseline } \\
0.61(0.47-0.78)^{*}\end{array}$ & $\begin{array}{c}6-9 \\
10-14 \\
15-18\end{array}$ & $\begin{array}{l}150(46.6) \\
143(37.4) \\
128(32.7)\end{array}$ & $\begin{array}{c}\text { Baseline } \\
0.67(0.51-0.93)^{\dagger} \\
0.56(0.41-0.75)^{*}\end{array}$ \\
\hline Neurodevelopmental & $\begin{array}{c}88(7.8) \\
(6.40-9.55)\end{array}$ & $\begin{array}{l}\text { Male } \\
\text { Female }\end{array}$ & $\begin{array}{l}54(8.2) \\
34(7.6)\end{array}$ & $\begin{array}{c}\text { Baseline } \\
0.92(0.59-1.44)\end{array}$ & $\begin{array}{c}6-9 \\
10-14 \\
15-18\end{array}$ & $\begin{array}{l}27(8.3) \\
29(7.5) \\
32(8.1)\end{array}$ & $\begin{array}{c}\text { Baseline } \\
0.91(0.52-1.56) \\
0.98(0.57-1.67)\end{array}$ \\
\hline Substance abuse & $\begin{array}{c}99(8.8) \\
(7.29-10.61)\end{array}$ & $\begin{array}{l}\text { Male } \\
\text { Female }\end{array}$ & $\begin{array}{c}65(10.3) \\
34(8)\end{array}$ & $\begin{array}{c}\text { Baseline } \\
0.75(0.49-1.16)\end{array}$ & $\begin{array}{c}6-9 \\
10-14 \\
15-18\end{array}$ & $\begin{array}{c}7(2.3) \\
17(4.6) \\
75(19.9)\end{array}$ & $\begin{array}{c}\text { Baseline } \\
2.10(0.86-5.13) \\
10.82(4.91-23.86)^{*}\end{array}$ \\
\hline Elimination & $\begin{array}{c}141(12.5) \\
(10.73-14.60)\end{array}$ & $\begin{array}{l}\text { Male } \\
\text { Female }\end{array}$ & $\begin{array}{l}94(14.3) \\
47(10.5)\end{array}$ & $\begin{array}{c}\text { Baseline } \\
0.70(0.48-1.02)\end{array}$ & $\begin{array}{c}6-9 \\
10-14 \\
15-18\end{array}$ & $\begin{array}{l}61(18.8) \\
47(12.1) \\
33(8.4)\end{array}$ & $\begin{array}{c}\text { Baseline } \\
0.60(0.39-0.90) \\
0.39(0.25-0.62)\end{array}$ \\
\hline Eating & $\begin{array}{c}3(0.3) \\
(0.09-0.08)\end{array}$ & $\begin{array}{l}\text { Male } \\
\text { Female }\end{array}$ & $\begin{array}{l}1(0.2) \\
2(0.5)\end{array}$ & $\begin{array}{c}\text { Baseline } \\
2.95(0.27-32.61)\end{array}$ & $\begin{array}{c}6-9 \\
10-14 \\
15-18\end{array}$ & $\begin{array}{c}- \\
- \\
3(0.8)\end{array}$ & $\begin{array}{c}\text { Baseline } \\
- \\
-\end{array}$ \\
\hline
\end{tabular}

OR $(95 \% \mathrm{Cl})=$ odds ratio $(95 \%$ confidence interval)

$* p<0.01 ;{ }^{\dagger} p \leqslant 0.05$.

ODD and ADHD reflect two separate disorders that frequently co-occur.

Furthermore, in line with previous reports, strong comorbidities were found in this study between ODD and separation anxiety disorder, generalized anxiety disorder, and depressive disorders. ${ }^{2,3,9,12,13}$ These findings show that ODD is closely related to separation anxiety disorder and generalized anxiety disorder, but not panic disorder, which can be justified by addressing abnormalities in different brain regions and considering different psychopathological pathways. ${ }^{26,27}$

Adjusted ORs of comorbidities for ODD were reported separately for gender and age-specific groups of children and adolescents in this study, which had not been assessed and presented in detail in previous studies. ${ }^{2,3}$ Higher prevalence rates of mood and anxiety disorders and lower prevalence rates of behavioral disorders were found among girls with ODD than boys with ODD, confirming previous studies that reported more internalizing comorbidities in girls and more externalizing comorbidities in boys with ODD. ${ }^{2,18,28}$ Boys may be more exposed to risk factors than girls for behavioral disorders, such as biological vulnerabilities and parental behaviors, ${ }^{18}$ and likewise in the case of girls for mood and anxiety disorders. ${ }^{28}$

In line with prior reports, mood disorders, psychotic disorders, and substance abuse disorders were significantly more common among 15-18-year-olds with ODD; however, anxiety disorders and behavioral disorders were significantly less prevalent among them. 1,2,29,30 Similarly, mood disorder rates were significantly higher among 10-14-year-olds with ODD than among 6-9-year-olds with ODD. Previous studies have shown that biological and psychological factors can produce higher depression rates at the onset of puberty, especially among adolescent girls. ${ }^{29}$ However, behavioral disorder rates were significantly lower among 10-14-year-olds with ODD, which is consistent with previous findings. ${ }^{1,29}$

Since few studies have been conducted to explain ODD comorbidity findings based on gender and age, this issue should be examined and extended in future studies.

In conclusion, this study provided new information about the prevalence, comorbidities, and sociodemographic predictors of ODD for researchers, clinicians, and healthcare policymakers. Data were collected from a face-to-face household survey of 30,532 children and adolescents aged 6-18 years from all provinces of Iran, based on a multistage cluster sampling design using the K-SADS-PL.

The sociodemographic predictors and comorbidities of ODD were estimated by logistic regression analysis, and the results showed that $3.9 \%$ of the sample met DSM-IV criteria for ODD. ODD was more common among boys and in late adolescence and was less prevalent in rural areas. Having a mother with a Master's degree or higher and/or a mother with no history of psychiatric 
hospitalization were protective factors for ODD in children and adolescents.

Of participants with ODD, $71.4 \%$ met the criteria for at least one other psychiatric disorder. Moreover, ODD was highly likely to co-occur with ADHD, separation anxiety disorder, generalized anxiety disorder, and depressive disorders. Therefore, since ODD is common among children and adolescents, more attention should be paid to providing preventive and treatment programs for ODD.

\section{Acknowledgements}

This study was supported by NIMAD (grant no. 940906). All Iranian universities with medical science programs were involved in the present study. Our special thanks go to our colleagues and the interviewers throughout Iran who were involved in this study. We would also like to thank all the participants and their families for their cooperation.

\section{Conflicts of interest}

The authors report no conflicts of interest.

\section{References}

1 American Psychiatric Association. Diagnostic and Statistical Manual of Mental Disorders, Fifth Edition (DSM-5). Arlington: American Psychiatric Publishing; 2013.

2 Boylan K, Vaillancourt T, Boyle M, Szatmari P. Comorbidity of internalizing disorders in children with oppositional defiant disorder. Eur Child Adolesc Psychiatry. 2007;16:484-94.

3 Maughan B, Rowe R, Messer J, Goodman R, Meltzer H. Conduct disorder and oppositional defiant disorder in a national sample: developmental epidemiology. J Child Psychol Psychiatry. 2004;45: 609-21.

4 Stahl ND, Clarizio HF. Conduct disorder and comorbidity. Psychol Sch. 1999;36:41-50.

5 Lavigne JV, Dahl KP, Gouze KR, LeBailly SA, Hopkins J. Multidomain predictors of oppositional defiant disorder symptoms in preschool children: cross-informant differences. Child Psychiatry Hum Dev. 2015;46:308-19.

6 Burnette ML. Gender and the development of oppositional defiant disorder: contributions of physical abuse and early family environment. Child Maltreat. 2013;18:195-204.

7 Greene RW, Biederman J, Zerwas S, Monuteaux MC, Goring JC, Faraone SV. Psychiatric comorbidity, family dysfunction, and social impairment in referred youth with oppositional defiant disorder. Am J Psychiatry. 2002;159:1214-24.

8 Demmer DH, Hooley M, Sheen J, McGillivray JA, Lum JA. Sex differences in the prevalence of oppositional defiant disorder during middle childhood: a meta-analysis. J Abnorm Child Psychol. 2017;45: 313-25.

9 Nock MK, Kazdin AE, Hiripi E, Kessler RC. Lifetime prevalence, correlates, and persistence of oppositional defiant disorder: results from the National Comorbidity Survey Replication. J Child Psychol Psychiatry. 2007;48:703-13.

10 Mohammadi MR, Ahmadi N, Salmanian M, Asadian-Koohestani F, Ghanizadeh A, Alavi A, et al. Psychiatric disorders in Iranian children and adolescents. Iran J Psychiatry. 2016;11:87-98.
11 Noordermeer SD, Luman M, Weeda WD, Buitelaar JK, Richards JS, Hartman CA, et al. Risk factors for comorbid oppositional defiant disorder in attention-deficit/hyperactivity disorder. Eur Child Adolesc Psychiatry. 2017;26:1155-64.

12 Riley M, Ahmed S, Locke A. Common questions about oppositional defiant disorder. Am Fam Physician. 2016;93:586-91.

13 Martin V, Granero R, Ezpeleta L. Comorbidity of oppositional defiant disorder and anxiety disorders in preschoolers. Psicothema. 2014;26: 27-32.

14 Harvey EA, Breaux RP, Lugo-Candelas Cl. Early development of comorbidity between symptoms of attention-deficit/hyperactivity disorder (ADHD) and oppositional defiant disorder (ODD). J Abnorm Psychol. 2016;125:154-67.

15 Sawyer SM, Azzopardi PS, Wickremarathne D, Patton GC. The age of adolescence. Lancet Child Adolesc Health. 2018;2:223-8.

16 Ghanizadeh A, Mohammadi MR, Yazdanshenas A. Psychometric properties of the Farsi translation of the Kiddie schedule for affective disorders and schizophrenia-present and lifetime version. BMC Psychiatry. 2006;6:10-10.

17 Mohammadi MR, Ahmadi N, Kamali K, Khaleghi A, Ahmadi A. Epidemiology of psychiatric disorders in Iranian children and adolescents (IRCAP) and its relationship with social capital, life style and parents' personality disorders: study protocol. Iran J Psychiatry. 2017;12:66-72.

18 Munkvold LH, Lundervold AJ, Manger T. Oppositional defiant disorder-gender differences in co-occurring symptoms of mental health problems in a general population of children. J Abnorm Child Psychol. 2011;39:577-87.

19 Lopez-Villalobos JA, Andres-De Llano JM, Lopez-Sanchez V, Rodriguez-Molinero L, Garrido-Redondo M, Martinez-Rivera MT, et al. Prevalence of oppositional defiant disorder in a sample of Spanish children between six and sixteen years: teacher's report. Actas Esp Psiquiatr. 2015;43:213-20.

20 Wilson MN, Hurtt CL, Shaw DS, Dishion TJ, Gardner F. Analysis and influence of demographic and risk factors on difficult child behaviors. Prev Sci. 2009;10:353-65.

21 Elgar FJ, Arlett C, Groves R. Stress, coping, and behavioural problems among rural and urban adolescents. J Adolesc. 2003;26:577-88.

22 Nelson DM, Coleman D, Corcoran K. Emotional and behavior problems in urban and rural adjudicated males: differences in risk and protective factors. Vict Offender. 2010;5:120-9.

23 Lee PC, Lee TC, Chen VC, Chen ML, Shih DH, Shao WC, et al. Quality of life in mothers of children with oppositional defiant symptoms: a community sample. Ment Health Fam Med. 2010;7:93-100.

24 Nordahl HM, Ingul JM, Nordvik H, Wells A. Does maternal psychopathology discriminate between children with DSM-IV generalised anxiety disorder or oppositional defiant disorder? The predictive validity of maternal axis I and axis II psychopathology. Eur Child Adolesc Psychiatry. 2007;16:87-95.

25 Ghanizadeh A. Conduct behaviors and oppositional defiant behaviors in children and adolescents with ADHD. Postgrad Med. 2015;127: 289-94.

26 Cui H, Zhang J, Liu Y, Li Q, Li H, Zhang L, et al. Differential alterations of resting-state functional connectivity in generalized anxiety disorder and panic disorder. Hum Brain Mapp. 2016;37:1459-73.

27 Maron E, Nutt D. Biological markers of generalized anxiety disorder. Dialogues Clin Neurosci. 2017;19:147-58.

28 Trepat E, Ezpeleta L. Sex differences in oppositional defiant disorder. Psicothema. 2011;23:666-71.

29 Park JH, Bang YR, Kim CK. Sex and age differences in psychiatric disorders among children and adolescents: high-risk students study. Psychiatry Investig. 2014;11:251-7.

30 Lawrence D, Johnson S, Hafekost J, Boterhoven De Haan K, Sawyer $\mathrm{M}$, Ainley J, et al. The mental health of children and adolescents. report on the second australian child and adolescent survey of mental health and wellbeing. Canberra: Department of Health; 2015. 